\title{
Fault-slip accumulation in an active rift over thousands to millions of years and the importance of paleoearthquake sampling
}

\author{
Vasiliki Mouslopoulou (1,3,4), Andrew Nicol (2), John Walsh (3), John Begg (2), Dougal Townsend (2), and \\ Dionissios Hristopulos (4) \\ (1) GFZ, Helmholtz-Centre Potsdam, Germany (vasso@gfz-potsdam.de), (2) GNS Science, PO Box 30368, Lower Hutt, New \\ Zealand (a.nicol@gns.cri.nz, j.begg@gns.cri.nz, d.townsend@gns).cri.nz, (3) School of Geological Sciences, University \\ College Dublin, Dublin 4, Ireland (john@fag.ucd.ie), (4) Department of Mineral Resources Engineering, Technical University \\ of Crete, 73100 Chania, Crete, Greece (dionisi@mred.tuc.gr)
}

The catastrophic earthquakes that recently (September 4th, 2010 and February 22nd, 2011) hit Christchurch, New Zealand, show that active faults, capable of generating large-magnitude earthquakes, can be hidden beneath the Earth's surface. In this study we combine near-surface paleoseismic data with deep $(<5 \mathrm{~km})$ onshore seismicreflection lines to explore the growth of normal faults over short $(<27 \mathrm{kyr})$ and long $(>1 \mathrm{Ma})$ timescales in the Taranaki Rift, New Zealand. Our analysis shows that the integration of different timescale datasets provides a basis for identifying active faults not observed at the ground surface, estimating maximum fault-rupture lengths, inferring maximum short-term displacement rates and improving earthquake hazard assessment. We find that fault displacement rates become increasingly irregular (both faster and slower) on shorter timescales, leading to incomplete sampling of the active-fault population. Surface traces have been recognised for $<50 \%$ of the active faults and along $50 \%$ of their lengths. The similarity of along-strike displacement profiles for short and long time intervals suggests that fault lengths and maximum single-event displacements have not changed over the last 3.6 Ma. Therefore, rate changes are likely to reflect temporal adjustments in earthquake recurrence intervals due to fault interactions and associated migration of earthquake activity within the rift. 